\title{
Effect of weedy rice at different densities on photosynthetic characteristics and yield of cultivated rice
}

\author{
X.M. XU*,+,\#, G. $\mathrm{LI}^{* *}, \#$, Y. SU*, and X.L. WANG ${ }^{* *}$ \\ College of Life Sciences, Nanjing Agricultural University, Nanjing, China* \\ Institute of Plant Protection, Jiangsu Academy of Agricultural Sciences, Nanjing, China**
}

\begin{abstract}
In order to evaluate effect of weedy rice on the photosynthesis and grain filling of cultivated rice, cultivated rice 'Nanjing 44' was planted in the field under different densities of weedy rice 'JS-Y1' for two years. The results showed that net photosynthetic rate $\left(P_{\mathrm{N}}\right)$, net assimilation rate, grain filling rate, and the grain yield of cultivated rice all decreased with increasing weedy rice density. Furthermore, yield component analysis revealed that increasing weedy rice density had the most significant effect on the percentage of filled grains and the number of rice panicles. The correlation analyses indicated that the yield of cultivated rice was highly correlated with the net photosynthetic rate and the net assimilation rate. Our results illustrated that high density of weedy rice might cause yield losses in cultivated rice by inhibition of photosynthesis and grain filling.
\end{abstract}

Additional key words: chlorophyll fluorescence; density; gas exchange; Oryza sativa; weedy rice; yield.

\section{Introduction}

Weedy rice (Oryza sativa L. $f$. spontanea), which is also known as red rice, is taxonomically related to cultivated rice (Oryza sativa L.) but grows taller and produces more tillers than cultivated rice and exhibits early seed shattering. In addition to these traits, the seeds of weedy rice are highly dormant, which enhances the reseeding rate and weedy characteristics of this species. In many riceplanting areas worldwide, particularly in Asia, South and North America, and southern Europe, weedy rice represents a major weed that is both persistent and noxious (Ferrero et al. 1999, Mortimer et al. 2000, Noldin 2000). Competition between rice and weedy rice depends on the rice cultivar as well as the weedy rice biotype, density, and emergence time (Jennings et al. 1968). Smith (1988) estimated that densities of 1 to 3 red rice plants $\mathrm{m}^{-2}$ represented a maximum infestation threshold for adequate control of losses in cultivated rice yield and quality. Pantone and Baker (1991) reported that 4,16 , and 25 red rice plants $\mathrm{m}^{-2}$ reduced the rice grain yield by 13,37 , and $48 \%$, respectively. Diarra et al. (1985) reported that weedy rice could cause the highest yield reduction in rice (about $80 \%$ ).

In past decades, weedy rice in China has been effectively managed because of the predominant use of the transplanting technique for rice cultivation (Zhang et al. 2000). In years, however, weedy rice populations have reemerged as a serious problem in northeast China and Jiangsu, Hainan Province (Sun et al. 2005, Wang et al. 2005, Yu et al. 2005). The available evidence confirms that weedy rice can cause serious yield losses because it competes with cultivated rice for resources, such as sun light, water, and nutrients, when the two species occur at the same fields (Zhang et al. 2006). Weedy rice acquires nitrogen from soil more efficiently than cultivated rice (Burgos et al. 2006) and is also known to have a negative effect on the grain quality of cultivated rice (Kwon et al. 1991, Pantone et al. 1991). Despite the importance of weedy rice in Asia, very little information is available on how cultivated rice responds to weedy rice of different

Received 24 June 2016, accepted 6 January 2017, published as online-first 8 February 2017.

${ }^{+}$Corresponding author; phone: +86- 25- 84395423, e-mail: xuxm@njau.edu.cn

Abbreviations: $\mathrm{Chl}$ - chlorophyll; $C_{\mathrm{i}}$ - intercellular $\mathrm{CO}_{2}$ concentration; ETR - electron transport rate; $\mathrm{F}_{\mathrm{v}} / \mathrm{F}_{\mathrm{m}}-$ maximal quantum yield of PSII photochemistry; $\mathrm{F}_{\mathrm{v}^{\prime}} / \mathrm{F}_{\mathrm{m}^{\prime}}$ - maximum photochemical efficiency of PSII in the light-adapted state, $g_{\mathrm{s}}$ - stomatal conductance; NAR - net assimilation rate; NPQ - nonphotochemical quenching; PIR - panicle increment rate; $P_{\mathrm{N}}$ - net photosynthetic rate; $\Phi_{\mathrm{PSII}}-$ actual photochemical efficiency of PSII; qP - photochemical quenching coefficient; RSS - ratio of source to sink increment.

Acknowledgements: This work was funded by the National Natural Science Foundation of China $(31272080,31501656)$ and the Special Fund for Agro-scientific Research in the Public Interest (201303022). We thank to R.J. Strasser for language correctness of the manuscript.

\#These authors contributed equally to this work. 
plant densities. We suppose that weedy rice may reduce cultivated rice yield due to inhibition of the photosynthetic productivity in cultivated rice at grain filling stages.

The objective of the current study was to investigate the effect of weedy rice as a function of different plant

\section{Materials and methods}

Plant material: The cultivated rice (Oryza sativa L. indica cv. 'Nanjing 44', China) seeds used in this study were obtained from the Institute of Food and Crops, Jiangsu Academy of Agricultural Science. The weedy rice (Oryza sativa L. $f$. spontanea JS-Y1) seeds used for the analysis were randomly collected from seeding rice fields in Xilai Bridge Town, Yangzhong City, Jiangsu Province in eastern China. The average plant height, panicle length, grains per panicle, panicle numbers per plant, and mass per 1,000 seeds of the weedy rice were $96.1 \mathrm{~cm}, 20.5 \mathrm{~cm}$, $101.4,17.0$, and $21.1 \mathrm{~g}$, respectively. The time from sowing to full heading stage was approximately $95 \mathrm{~d}$, and the average germination rate was $44.5 \%$. As an indica rice, weedy rice has a dark red caryopsis that drops easily after maturation.

Field study: The experiment was carried out in 2014 and 2015 at an experimental rice field of the Institute of Crop Protection, Jiangsu Academy of Agricultural Science, Jiangsu Province, China. The soil type at the site is horse liver soil with a $\mathrm{pH}$ of 7.5. The organic content, effective nitrogen content, total phosphorus $\left(\mathrm{P}_{2} \mathrm{O}_{5}\right)$, and total potassium $\left(\mathrm{K}_{2} \mathrm{O}\right)$ are $11.0 \mathrm{~g} \mathrm{~kg}^{-1}, 5.1 \mathrm{~g} \mathrm{~kg}^{-1}, 1.3 \mathrm{~g} \mathrm{~kg}^{-1}$, and $6.6 \mathrm{~g} \mathrm{~kg}^{-1}$, respectively. In present study, we only showed data from 2015 because of the climatic fluctuation. The average day/night air temperature was $32 / 24^{\circ} \mathrm{C}$, the average number of sun hours was $8 \mathrm{~h}$ and the $\mathrm{CO}_{2}$ concentration was about $400 \mu \mathrm{mol} \mathrm{mol}{ }^{-1}$. The plots were manually filled with water to the same level $(5-10 \mathrm{~cm}$ depth) and other culturing methods were performed according to field conventions.

The pots were arranged in a randomized complete block design with four replications according to the methodology described by Li (2001). The competition level (five treatments) was assigned based on the proportion of weedy rice population in each pot. Weedy and cultivated rice seeds were presoaked in tap water for 2 or $3 \mathrm{~d}$ before sowing, and both rice types were sowed in $1 \mathrm{~m}^{2}$ plots $(1 \mathrm{~m} \times 1 \mathrm{~m})$ at the same time. Each plot consisted of four rows planted $25 \mathrm{~cm}$ apart. The cultivated rice was planted 15-20 plants per row, corresponding to a standard density of $60-80$ plants $\mathrm{m}^{-2}$, then artificially infested at the one-leaf stage to achieve a target density of 60 plants $\mathrm{m}^{-2}$ (15 plants per row). Weedy rice was evenly distributed between the rows of cultivated rice, and five density levels were analyzed: $0,2,4,6$, and 8 weedy rice plants $\mathrm{m}^{-2}$. The experiment included 20 total plots (replicates) in a field layout. Experiments were carried out at all stages of development of cultivated rice and weedy rice. densities on the photosynthetic characteristics and grain filling of cultivated rice. We also explored the physiological mechanisms by which weedy rice reduces the yield of cultivated rice in view of photosynthetic production.

Chlorophyll (Chl) content: At the tillering and grainfilling stages of cultivated rice, Chl content was measured using a SPAD-502 portable Chl meter (Minolta, Japan). For the Chl content evaluation, ten plants at the same developmental stage were selected within each district to measure the flag leaf $\mathrm{Chl}$ content, with three replicates performed for each measurement.

Gas exchange and $\mathrm{Chl}$ fluorescence measurements: At the tillering and grain-filling stages, gas-exchange parameters and the net photosynthetic rates $\left(P_{\mathrm{N}}\right)$ of flag leaves were measured from 8:00 to $11: 30 \mathrm{~h}$ using a portable infrared gas analyzer in open system mode (LI-6400, LI-COR Inc., Lincoln, NE, USA). The leaf temperature during measurements was maintained at $27.0 \pm 0.1^{\circ} \mathrm{C}$, and PPFD was $1,200 \mu \mathrm{mol} \mathrm{m} \mathrm{m}^{-2} \mathrm{~s}^{-1}$. Chl $a$ fluorescence in intact leaves was measured with a portable pulse-modulated fluorometer (FMS-2, Hansatech, King's Lynn, UK). Leaf clips were used to adapt individual leaves to darkness for $30 \mathrm{~min}$. After the dark period, all centers of PSII were “open'. The minimum Chl fluorescence $\left(F_{o}\right)$ was measured on the abaxial leaf surface, whereas the maximum fluorescence $\left(\mathrm{F}_{\mathrm{m}}\right)$ corresponding to all PSII centers in the "closed state" was induced by a 0.8 -s pulse of saturating irradiance $\left[4,000 \mu \mathrm{mol}\right.$ (photon) $\left.\mathrm{m}^{-2} \mathrm{~s}^{-1}\right]$. Ten readings were taken per pot each sampling day. The calculations of parameters were made according to the equations of Genty et al. (1989), Bilger and Björkman (1990), and Schreiber et al. (1994):

$$
\begin{aligned}
& \mathrm{F}_{\mathrm{v}} / \mathrm{F}_{\mathrm{m}}=\left(\mathrm{F}_{\mathrm{m}}-\mathrm{F}_{\mathrm{o}}\right) / \mathrm{F}_{\mathrm{m}} \\
& \mathrm{F}_{\mathrm{v}^{\prime}} / \mathrm{F}_{\mathrm{m}^{\prime}}=\left(\mathrm{F}_{\mathrm{m}^{\prime}}-\mathrm{F}_{\mathrm{o}^{\prime}}\right) / \mathrm{F}_{\mathrm{m}^{\prime}} \\
& \Phi_{\mathrm{PSII}}=\left(\mathrm{F}_{\mathrm{m}^{\prime}}-\mathrm{F}_{\mathrm{s}}\right) / \mathrm{F}_{\mathrm{m}^{\prime}} \\
& \mathrm{NPQ}=\mathrm{F}_{\mathrm{m}} / \mathrm{F}_{\mathrm{m}^{\prime}}-1 \\
& \mathrm{q}_{\mathrm{P}}=\left(\mathrm{F}_{\mathrm{m}^{\prime}}-\mathrm{F}_{\mathrm{s}}\right) /\left(\mathrm{F}_{\mathrm{m}^{\prime}}-\mathrm{F}_{\mathrm{o}^{\prime}}\right) \\
& \mathrm{ETR}=\Phi_{\mathrm{PS}} \times \mathrm{PAR} \times 0.5 \times 0.84
\end{aligned}
$$

Net assimilation rate and panicle increment rate: At the grain-filling stage, the net assimilation rate (NAR) and panicle increment rate (PIR) were measured according to the method of Zhai et al. (2002). Five labeled shoots with uniform panicles were sampled every $7 \mathrm{~d}$ from heading to harvest. Leaf areas were first measured using an $L I-3000 C$ portable area meter (LI-COR Inc., Lincoln NE, USA). Thereafter, plants were separated into grains and nutritious organs (non-grain organs, including stems, leaves, and sheathes), dried in an oven at $80^{\circ} \mathrm{C}$ for $48 \mathrm{~h}$, and then weighed for growth analysis. Panicles were divided into upper, middle, and lower parts according to the method of 
Huang et al. (1998). NAR and PIR were calculated as follows:

$$
\begin{aligned}
& \mathrm{NAR}=(\mathrm{M} 2-\mathrm{M} 1) /[0.5 \times(\mathrm{S} 1+\mathrm{S} 2) \times \mathrm{D}] \\
& \mathrm{PIR}=(\mathrm{G} 2-\mathrm{G} 1) /[0.5 \times(\mathrm{S} 1+\mathrm{S} 2) \times \mathrm{D}]
\end{aligned}
$$

where $\mathrm{M} 1$ and $\mathrm{M} 2, \mathrm{G} 1$ and $\mathrm{G} 2$, and $\mathrm{S} 1$ and $\mathrm{S} 2$ represent shoot biomass, dry matter mass per panicle, and leaf area per stem, respectively, for the first and the second measurements. D indicates the number of days between the two measurements.

Source and sink increment ratio: At the grain-filling stage, source and sink increment ratio determination was performed according to the method of Cao et al. (2002) using the following equation:

$$
\mathrm{RSS}=(\mathrm{M} 2-\mathrm{M} 1) /(\mathrm{G} 2-\mathrm{G} 1),
$$

\section{Results}

Chl content and photosynthetic characteristics: Although there were no significant differences in Chl contents between cultivated rice grown with weedy rice at different densities and the control $\left(0\right.$ plants $\left.\mathrm{m}^{-2}\right)$ at the tillering and grain-filling stages (Table 1), differences in the gas-exchange parameters were observed. Specifically, the rate of photosynthesis was reduced by weedy rice interference at both stages, and stomatal conductance $\left(g_{\mathrm{s}}\right)$ was reduced at the tillering stage. $C_{\mathrm{i}}$ of cultivated rice under the five weedy rice densities were similar for both the tillering and grain-filling stage, and no significant differences were observed for weedy rice densities lower than 6 plants $\mathrm{m}^{-2}$. Additionally, statistical analysis indicated that various $\mathrm{Chl}$ fluorescence parameters, such as $\mathrm{F}_{\mathrm{v}^{\prime}} / \mathrm{F}_{\mathrm{m}^{\prime}}, \Phi_{\mathrm{PSII}}$, and ETR, were significantly different for cultivated rice grown with weedy rice compared with the control $\left(0\right.$ plants $\left.\mathrm{m}^{-2}\right)$ at the tillering stage. No significant differences were observed for $F_{v} / F_{m}$ at the tillering stage where RSS is a ratio of source to sink in increment, and M1 and M2 (G1 and G2) represent shoot biomass (dry mass per panicle) at 28 or $35 \mathrm{~d}$ after the heading measurements, respectively. The methods used for sample selection, drying, and weighing are as described in the methods section above.

Statistical analysis was performed using SPSS 18.0 software for Windows (SPSS, Chicago, IL). Data under the five weedy rice densities were analyzed using one way analysis of variance (ANOVA) followed by Duncan's multiple range test (DMRT) $(P<0.05$ for significant differences). Correlation and linear regression analyses were performed using Excel 2010 software. All the measurements were performed three times for each treatment.

and for nearly all the parameters at the grain-filling stage (Table 2).

Statistics for cultivated rice yield: The grain yield of cultivated rice was measured during the 2014-2015 experiment and ranged from $8,460.5 \mathrm{~kg} \mathrm{ha}^{-1}$ to $3,372.3 \mathrm{~kg}$ $\mathrm{ha}^{-1}$ for weedy rice densities ranging from $0-8$ plants $\mathrm{m}^{-2}$. The presence of weedy rice at $2,4,6$, and 8 plants per $\mathrm{m}^{2}$ reduced cultivated rice production by $24.9,31.4,33.7$, and $60.1 \%$, respectively. Thus, weedy rice had a significant impact on the production of cultivated rice (Table 3 ). Furthermore, yield component analysis indicated that the effective number of panicles $\mathrm{m}^{-2}$ and the seed-setting rate were affected by weedy rice, when the density of weedy rice was greater than 2 and 4 plants $\mathrm{m}^{-2}$, respectively. In contrast, significant differences in the mass of 1,000 grain and number of grains per panicle relative to the control were only observed under a density of 8 plants $\mathrm{m}^{-2}$.

Table 1. Effect of different weedy rice densities on the chlorophyll content, photosynthetic parameters of cultivated rice at the tillering and grain filling stages. Means followed by the same letter within same parameter were not significantly different at $P>0.05$. And different letter indicates significantly different at $P<0.05$. Chl - chlorophyll; $P_{\mathrm{N}}-$ net photosynthetic rate; $g_{\mathrm{s}}-$ stomatal conductance; $C_{\mathrm{i}}$ - intercellular $\mathrm{CO}_{2}$ concentration.

\begin{tabular}{llllll}
\hline Stage & $\begin{array}{l}\text { Density } \\
{\left[\text { plants } \mathrm{m}^{-2}\right]}\end{array}$ & $\begin{array}{l}\text { Chl content } \\
{[\mathrm{SPAD}]}\end{array}$ & $\begin{array}{l}P_{\mathrm{N}} \\
{\left[\mu \mathrm{mol}\left(\mathrm{CO}_{2}\right) \mathrm{m}^{-2} \mathrm{~s}^{-1}\right]}\end{array}$ & $\begin{array}{l}g_{\mathrm{s}} \\
{\left[\mathrm{mol}\left(\mathrm{H}_{2} \mathrm{O}\right) \mathrm{m}^{-2} \mathrm{~s}^{-1}\right]}\end{array}$ & $\begin{array}{l}C_{\mathrm{i}} \\
{\left[\mu \mathrm{mol}\left(\mathrm{CO}_{2}\right) \mathrm{mol}^{-1}\right]}\end{array}$ \\
\hline Tillering & 0 & $42.26 \pm 2.03^{\mathrm{a}}$ & $28.16 \pm 0.69^{\mathrm{a}}$ & $0.43 \pm 0.01^{\mathrm{a}}$ & $325.78 \pm 4.18^{\mathrm{a}}$ \\
& 2 & $41.59 \pm 1.87^{\mathrm{a}}$ & $27.82 \pm 0.36^{\mathrm{ab}}$ & $0.44 \pm 0.01^{\mathrm{a}}$ & $324.00 \pm 3.24^{\mathrm{a}}$ \\
& 4 & $41.62 \pm 1.50^{\mathrm{a}}$ & $27.01 \pm 0.12^{\mathrm{bc}}$ & $0.35 \pm 0.01^{\mathrm{b}}$ & $320.00 \pm 8.76^{\mathrm{a}}$ \\
& 6 & $40.30 \pm 1.38^{\mathrm{a}}$ & $26.67 \pm 0.37^{\mathrm{c}}$ & $0.34 \pm 0.03^{\mathrm{b}}$ & $325.33 \pm 2.66^{\mathrm{a}}$ \\
& 8 & $41.52 \pm 1.89^{\mathrm{a}}$ & $26.47 \pm 0.23^{\mathrm{c}}$ & $0.28 \pm 0.07^{\mathrm{c}}$ & $313.33 \pm 0.58^{\mathrm{b}}$ \\
& 0 & $42.75 \pm 1.79^{\mathrm{a}}$ & $24.52 \pm 1.14^{\mathrm{a}}$ & $0.53 \pm 0.02^{\mathrm{a}}$ & $302.89 \pm 1.05^{\mathrm{a}}$ \\
& 2 & $42.80 \pm 2.01^{\mathrm{a}}$ & $24.37 \pm 0.45^{\mathrm{a}}$ & $0.53 \pm 0.03^{\mathrm{a}}$ & $297.67 \pm 4.36^{\mathrm{b}}$ \\
& 4 & $42.10 \pm 1.67^{\mathrm{a}}$ & $23.83 \pm 0.67^{\mathrm{ab}}$ & $0.55 \pm 0.06^{\mathrm{a}}$ & $303.33 \pm 3.91^{\mathrm{a}}$ \\
& 6 & $41.89 \pm 2.60^{\mathrm{a}}$ & $23.83 \pm 0.62^{\mathrm{ab}}$ & $0.60 \pm 0.02^{\mathrm{b}}$ & $295.11 \pm 2.93^{\mathrm{b}}$ \\
& 8 & $42.17 \pm 2.32^{\mathrm{a}}$ & $23.29 \pm 0.92^{\mathrm{b}}$ & $0.60 \pm 0.04^{\mathrm{b}}$ & $288.78 \pm 4.12^{\mathrm{c}}$ \\
\hline
\end{tabular}


Table 2. Effect of different weedy rice densities on the chlorophyll fluorescence parameters of cultivated rice at the tillering and grain filling stages. Means followed by the same letter within same parameter were not significantly different at $P>0.05$. And different letter indicates significantly different at $P<0.05 . \mathrm{F}_{\mathrm{v}} / \mathrm{F}_{\mathrm{m}}$ - maximal quantum yield of PSII photochemistry; $\mathrm{F}_{\mathrm{v}^{\prime}} / \mathrm{F}_{\mathrm{m}^{\prime}}-$ maximum photochemical efficiency of PSII in the light-adapted state; NPQ - nonphotochemical quenching; qP - photochemical quenching coefficient; $\Phi_{P S I I}-$ actual photochemical efficiency of PSII; ETR - electron transport rate.

\begin{tabular}{|c|c|c|c|c|c|c|c|}
\hline Stage & $\begin{array}{l}\text { Density } \\
\text { [plants } \mathrm{m}^{-2} \text { ] }\end{array}$ & $\mathrm{F}_{\mathrm{v}} / \mathrm{F}_{\mathrm{m}}$ & $\mathrm{F}_{\mathrm{v}}^{\prime} / \mathrm{F}_{\mathrm{m}}{ }^{\prime}$ & NPQ & $\mathrm{qP}$ & $\Phi_{\text {PSII }}$ & ETR \\
\hline \multirow[t]{5}{*}{ Tillering } & 0 & $0.852 \pm 0.003^{\mathrm{a}}$ & $0.68 \pm 0.02^{\mathrm{a}}$ & $1.42 \pm 0.20^{\mathrm{a}}$ & $0.90 \pm 0.02^{\mathrm{a}}$ & $0.58 \pm 0.02^{\mathrm{a}}$ & $169.46 \pm 7.17^{\mathrm{a}}$ \\
\hline & 2 & $0.854 \pm 0.003^{\mathrm{a}}$ & $0.63 \pm 0.02^{b}$ & $1.96 \pm 0.28^{\mathrm{b}}$ & $0.88 \pm 0.01^{\mathrm{ab}}$ & $0.50 \pm 0.04^{\mathrm{b}}$ & $146.38 \pm 12.08^{\mathrm{bc}}$ \\
\hline & 4 & $0.852 \pm 0.005^{\mathrm{a}}$ & $0.62 \pm 0.04^{b}$ & $2.10 \pm 0.38^{b}$ & $0.83 \pm 0.02^{\mathrm{d}}$ & $0.45 \pm 0.04^{\mathrm{c}}$ & $131.92 \pm 10.31^{\mathrm{c}}$ \\
\hline & 6 & $0.858 \pm 0.006^{\mathrm{a}}$ & $0.63 \pm 0.03^{b}$ & $1.95 \pm 0.41^{b}$ & $0.83 \pm 0.02^{\mathrm{cd}}$ & $0.49 \pm 0.04^{b c}$ & $142.62 \pm 11.44^{\mathrm{bc}}$ \\
\hline & 8 & $0.857 \pm 0.003^{\mathrm{a}}$ & $0.63 \pm 0.03^{b}$ & $1.77 \pm 0.27^{\mathrm{ab}}$ & $0.85 \pm 0.02^{\mathrm{bc}}$ & $0.49 \pm 0.04^{\mathrm{bc}}$ & $151.59 \pm 12.39^{b}$ \\
\hline \multirow[t]{5}{*}{ Grain filling } & 0 & $0.862 \pm 0.003^{\mathrm{a}}$ & $0.62 \pm 0.01^{\mathrm{a}}$ & $2.38 \pm 0.34^{\mathrm{a}}$ & $0.85 \pm 0.05^{\mathrm{a}}$ & $0.46 \pm 0.03^{\mathrm{a}}$ & $200.96 \pm 3.32^{\mathrm{a}}$ \\
\hline & 2 & $0.864 \pm 0.003^{\mathrm{a}}$ & $0.64 \pm 0.01^{\mathrm{a}}$ & $2.05 \pm 0.08^{\mathrm{a}}$ & $0.83 \pm 0.02^{\mathrm{ab}}$ & $0.48 \pm 0.02^{\mathrm{a}}$ & $202.31 \pm 9.82^{\mathrm{a}}$ \\
\hline & 4 & $0.862 \pm 0.003^{\mathrm{a}}$ & $0.63 \pm 0.02^{\mathrm{a}}$ & $2.43 \pm 0.40^{\mathrm{a}}$ & $0.84 \pm 0.01^{\mathrm{ab}}$ & $0.45 \pm 0.03^{\mathrm{a}}$ & $194.50 \pm 6.00^{\mathrm{a}}$ \\
\hline & 6 & $0.863 \pm 0.003^{\mathrm{a}}$ & $0.64 \pm 0.01^{\mathrm{a}}$ & $2.14 \pm 0.31^{\mathrm{a}}$ & $0.84 \pm 0.03^{\mathrm{ab}}$ & $0.48 \pm 0.03^{\mathrm{a}}$ & $200.57 \pm 12.06^{\mathrm{a}}$ \\
\hline & 8 & $0.865 \pm 0.006^{\mathrm{a}}$ & $0.63 \pm 0.03^{\mathrm{a}}$ & $2.19 \pm 0.48^{\mathrm{a}}$ & $0.80 \pm 0.02^{\mathrm{b}}$ & $0.46 \pm 0.05^{\mathrm{a}}$ & $191.76 \pm 19.36^{\mathrm{a}}$ \\
\hline
\end{tabular}

Table 3. Variations in the yield components of cultivated rice under different weedy rice densities. Means followed by the same letter within same parameter were not significantly different at $P>0.05$. And different letter indicates significantly different at $P<0.05$.

\begin{tabular}{lllllll}
\hline $\begin{array}{l}\text { Density } \\
\text { [plants } \mathrm{m}^{-2} \text { ] }\end{array}$ & $\begin{array}{l}\text { Seed setting rate } \\
{[\%]}\end{array}$ & $\begin{array}{l}\text { Mass } \\
{[\mathrm{g} \text { per 1,000 seeds] }]}\end{array}$ & $\begin{array}{l}\text { Grains } \\
{[\text { number per panicle] }]}\end{array}$ & $\begin{array}{l}\text { Effective panicles } \\
{\left[\text { number per m }{ }^{2}\right]}\end{array}$ & $\begin{array}{l}\text { Grain yield } \\
{\left[\mathrm{kg} \mathrm{ha}^{-1}\right]}\end{array}$ & $\begin{array}{l}\text { Yield loss rate } \\
{[\%]}\end{array}$ \\
\hline 0 & $95.91 \pm 0.46^{\mathrm{a}}$ & $28.77 \pm 0.23^{\mathrm{a}}$ & $113.86 \pm 6.03^{\mathrm{a}}$ & $398 \pm 60.40^{\mathrm{a}}$ & $8,460.5 \pm 337.1^{\mathrm{a}}$ & 0 \\
2 & $94.98 \pm 0.50^{\mathrm{a}}$ & $28.90 \pm 0.55^{\mathrm{a}}$ & $113.96 \pm 8.30^{\mathrm{a}}$ & $312 \pm 49.11^{\mathrm{ab}}$ & $6,350.3 \pm 788.7^{\mathrm{b}}$ & 24.94 \\
4 & $94.76 \pm 0.62^{\mathrm{a}}$ & $28.54 \pm 0.22^{\mathrm{a}}$ & $107.96 \pm 8.49^{\mathrm{ab}}$ & $306 \pm 21.21^{\mathrm{b}}$ & $5,804.3 \pm 510.8^{\mathrm{b}}$ & 31.40 \\
6 & $91.45 \pm 1.25^{\mathrm{b}}$ & $28.75 \pm 0.33^{\mathrm{a}}$ & $107.58 \pm 6.50^{\mathrm{ab}}$ & $294 \pm 37.47^{\mathrm{b}}$ & $5,610.2 \pm 872.1^{\mathrm{b}}$ & 33.69 \\
8 & $90.39 \pm 0.30^{\mathrm{b}}$ & $27.01 \pm 0.82^{\mathrm{b}}$ & $96.52 \pm 6.43^{\mathrm{b}}$ & $220 \pm 36.17^{\mathrm{b}}$ & $3,372.3 \pm 506.1^{\mathrm{c}}$ & 60.14 \\
\hline
\end{tabular}

Photosynthetic performance and grain-filling after heading: The maximum net photosynthetic rate of cultivated rice occurred nearly $15 \mathrm{~d}$ after heading, then decreased steadily as grain filling progressed (Fig. 1A). Differences in the photosynthetic rate of cultivated rice between the control and treatments were significantly greater in the late heading stage than that in the early heading stage. Regression analysis showed that the net photosynthetic rates at both the tillering and grain-filling stages were positively associated with the yield (Fig. 1B). The NAR of cultivated rice under different densities of weedy rice decreased markedly as grain filling progressed, with greater decreases under higher weedy rice densities (Fig. 2A). The PIR increased approximately 14-21 d after heading and subsequently decreased during the late part of grain filling process (Fig. $2 B$ ). In addition, the cultivated rice yield was more highly correlated with NAR (Fig. $2 C$ ) than with the PIR (Fig. 2D).
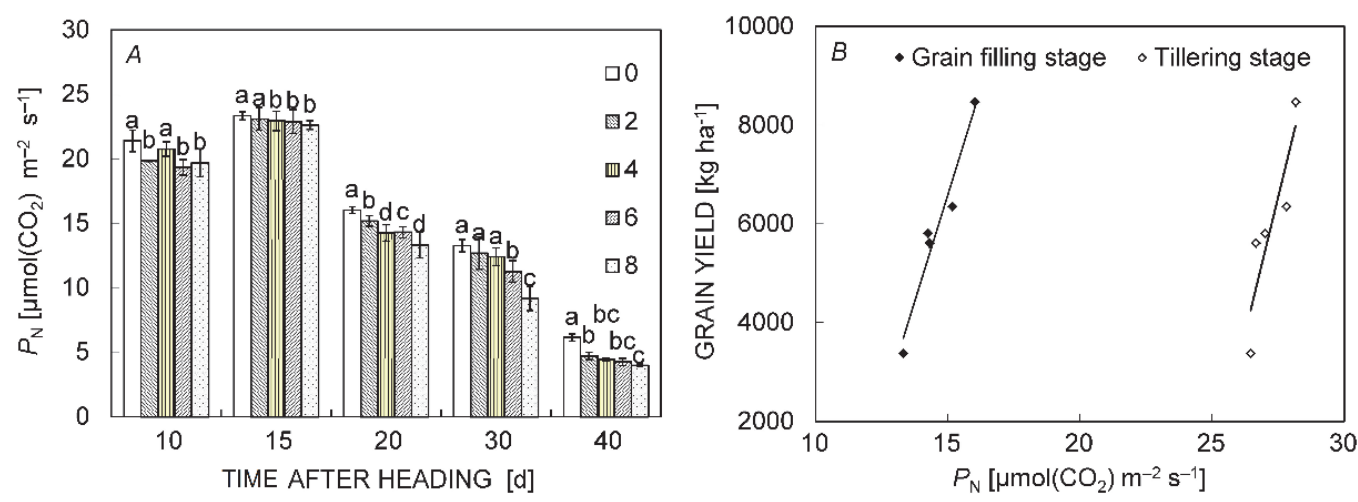

Fig. 1. Net photosynthetic rate $\left(P_{\mathrm{N}}\right)(A)$ of cultivated rice under different weedy rice densities. The relationship $(B)$ between yield and $P_{\mathrm{N}}$ of cultivated rice at the tillering stage (white rhombus) and the grain filling stage (black rhombus). Bars represent the means $\pm \mathrm{SE}$ of three replicates. Different letters indicate a significantly difference $(P<0.05)$ among lines by Duncan's test . 

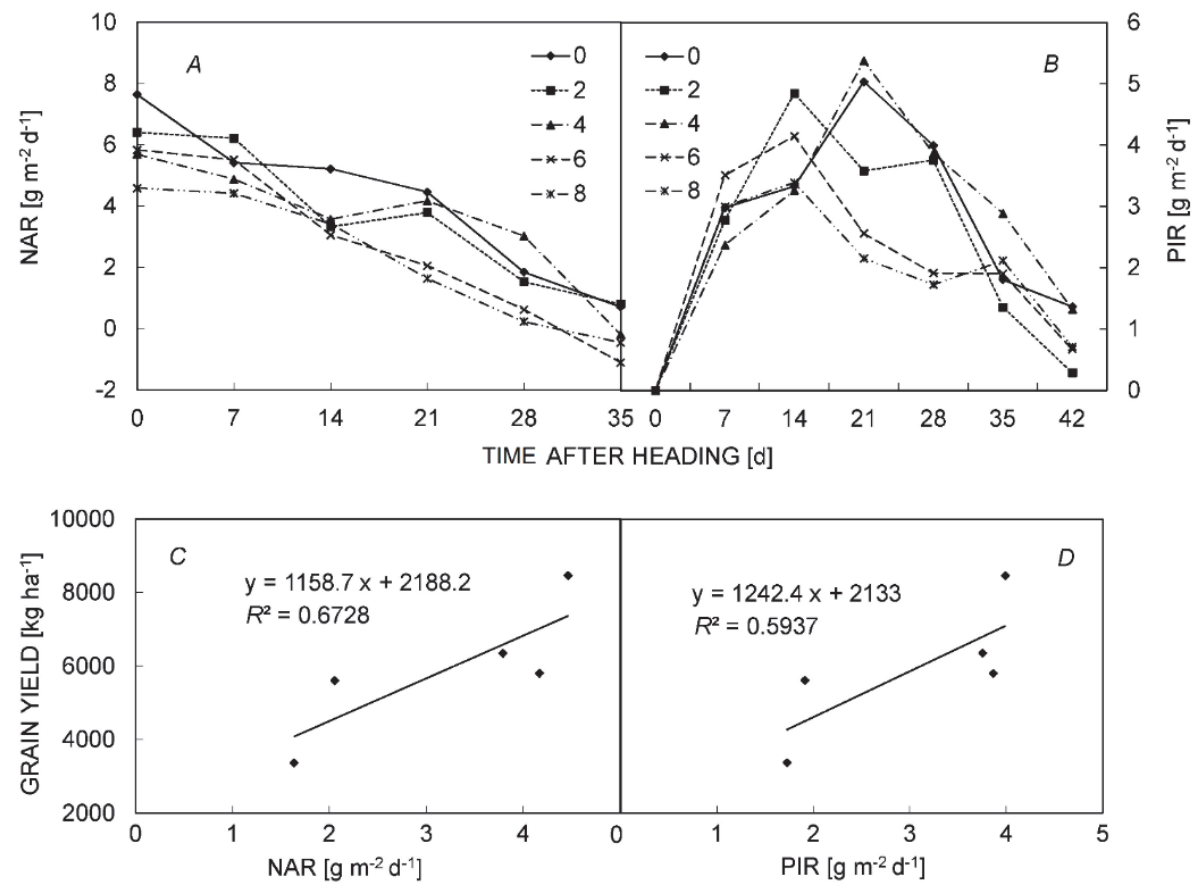

Fig. 2. Changes in the net assimilation rate (NAR) $(A)$ and panicle increment rate (PIR) $(B)$ of cultivated rice during the grouting process under different weedy rice densities. The relationship between yield and NAR $(C)$ or PIR $(D)$. Points represent the means \pm SE of three replicates.

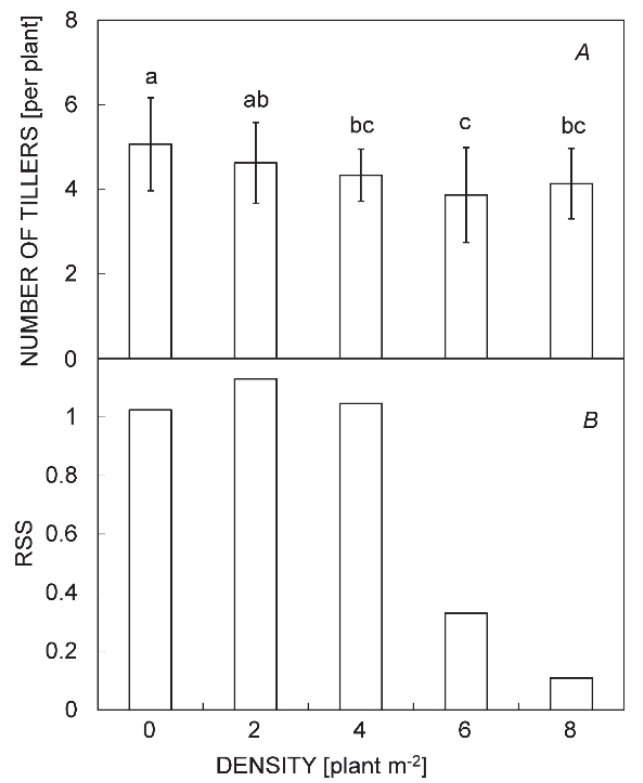

Fig. 3. The number of tillers $(A)$ and RSS $(B)$ of cultivated rice under different weedy rice densities. Bars represent the means \pm $\mathrm{SE}$ of three replicates.

\section{Discussion}

As crops derive directly or indirectly from photosynthetic products, photosynthesis is ultimately the basis of crop production and yield (Wang et al. 2015). In the present study, photosynthetic characteristics of cultivated rice
Impact of weedy rice on the tiller number and RSS of cultivated rice: Weedy rice density had significant effects on the number of tillers in cultivated rice (Fig. $3 A$ ). The ratio of source to sink in increment (RSS) in cultivated rice was affected by weedy rice density, with values close to 1 at weedy rice densities of 0,2 , and 4 plants $\mathrm{m}^{-2}$ and values further away from 1 at densities of 6 and 8 plants $\mathrm{m}^{-2}$ (Fig. 3B).

Relationships between yield and yield component, tiller number and RSS: The effective panicle number of cultivated rice, a determinant of rice yield, was found to have a higher relative correlation $\left(R^{2}=0.99\right)$ through linear analysis with rice yield (Fig. $4 A$ ). Moreover, a positive correlation was observed between rice yield and the seedsetting rate $\left(R^{2}=0.74\right)($ Fig. $4 B)$ or $\operatorname{RSS}\left(R^{2}=0.57\right)$ (Fig. $4 C$ ), indicating that the seed-setting rate was the more important factor affecting the rice yield. In addition to these findings, positive correlations between effective panicle number and the number of tillers were observed (Fig. 4D). The RSS was also positively correlated with the seed-setting rate $\left(R^{2}=0.95\right)$ (Fig. $\left.4 E\right)$.

were affected by weedy rice density. However, the final rice yield was more highly correlated with the net photosynthetic rate during the grain-filling process than during the tillering stages. These findings demonstrated 

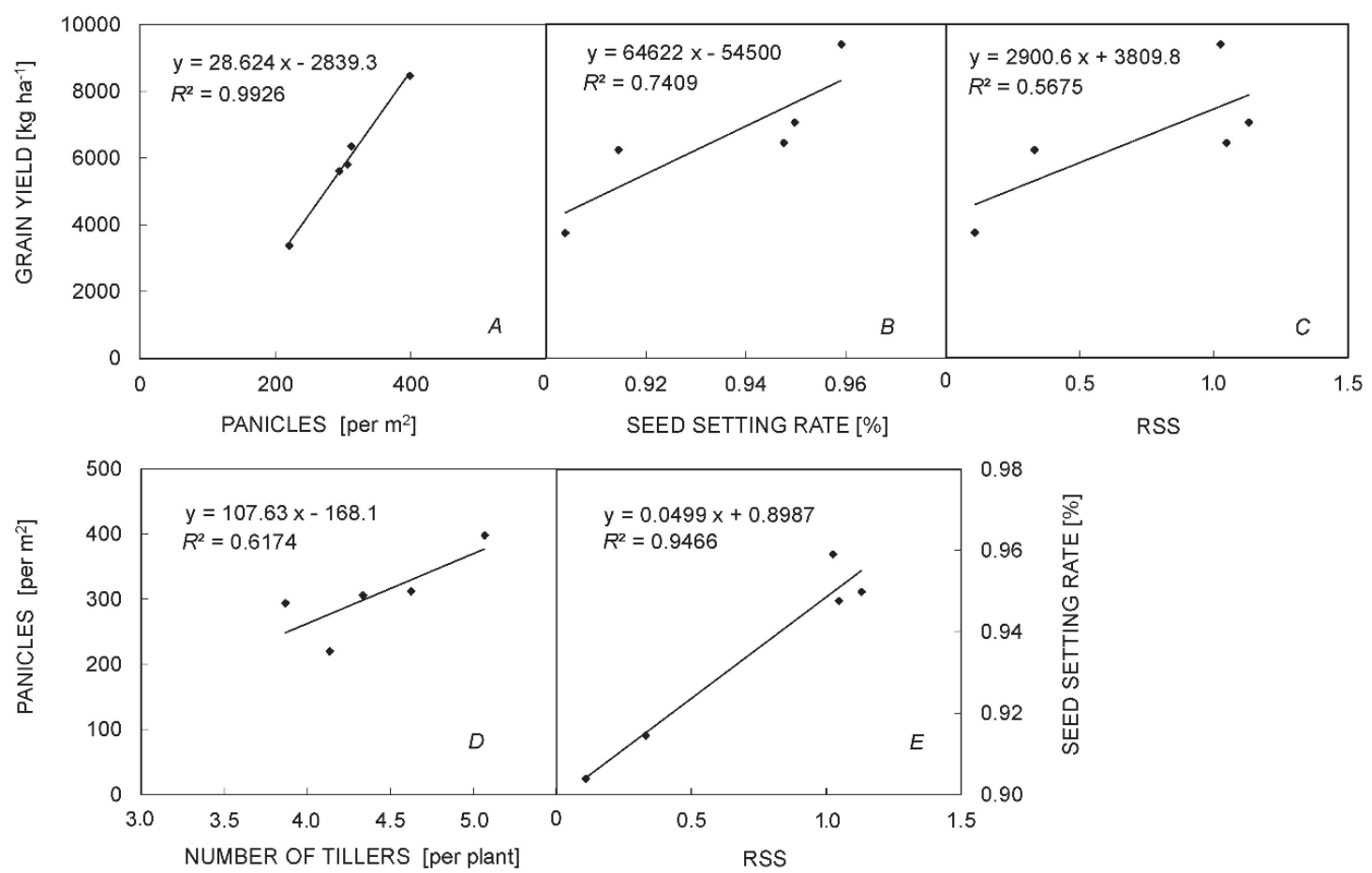

Fig. 4. Correlations between rice yield and number of panicles $(A)$, seed setting rate $(B)$, and RSS $(C)$, panicles and tillers $(D)$, seed setting rate and RSS $(E)$. Points represent the means \pm SE of three replicates.

that the reduced photosynthetic rate under high densities of weedy rice was associated with a serious decline in rice production. One reason for decreased photosynthetic performance could be fact that weedy rice became a more aggressive competitor at the tillering and grain-filling stage, causing shading and nutrient stress to cultivated rice. At the filling stage, cultivated rice plants were shorter $(42.1 \mathrm{~cm})$ than those of weedy rice $(48.9 \mathrm{~cm})$, which also provided a lower shoot biomass ( $3.4 \mathrm{~g}$ per plant) than that of weedy rice ( $6.5 \mathrm{~g}$ per plant). The canopy of cultivated rice and weedy rice already started overlapping; weedy rice exerted severe competition for light. Moreover, there is strong evidence from previous research that weedy rice is a much stronger competitor for nitrogen than cultivated rice (Estorninos et al. 2002, Chauhan 2011); weedy rice acquires more $\mathrm{N}$, and has higher $\mathrm{N}$-use efficiency for biomass production than that of rice. These factors resulted in reduced assimilative capacity of cultivated rice.

Grain yield depends mainly on photosynthates after heading, which in turn depends on $\mathrm{CO}_{2}$ assimilation capacity (Dai et al. 2003). Thus, the grain-filling stage is a critical period of photosynthetic product accumulation in crops. The present study suggests that while the filling grains of crops demands large amounts of photosynthates, there is a rapid decline in leaf photosynthetic function, leading to a decreased yield (Zhang et al. 2001). In this study, we investigated the possible physiological mechanisms by which weedy rice affects cultivated rice yield in terms of photosynthesis. The yield of cultivated rice decreased as the density of weedy rice increased. Yield component analysis showed that reductions in effective panicle number and the seed-setting rate were the main reasons for the decrease in the rice yield. On one hand, significant differences in the number of tillers at the tillering stage were observed under different weedy rice densities, indicating a significant positive correlation between the number of tillers and effective panicle number. However, the seed-setting rate and the sourcesink incremental ratio were also positively correlated. Previous studies demonstrated that RSS values close to 1 correlated with grain plumpness and a higher seed-setting rate (Xu et al.1999). RSS of cultivated rice under 0, 2, 4, 6 , and 8 weedy rice plants $\mathrm{m}^{-2}$ were $1.02,1.13,1.05,0.32$, and 0.11 , respectively. These results support the hypothesis that RSS values further away from 1 are indicative of reduced grain plumpness and lower seed-setting rates. Greater differences were observed as the density of weedy rice increased, which was consistent with the yield component analysis. In summary, a significant reduction in the net photosynthetic rate of rice by weedy rice and the increasingly reduced RSS values resulted in insufficient photosynthate accumulation for grain filling and premature movement of materials stored in the stem and tillers to the grain, ultimately affecting grain-filling and the seedsetting rate. Moreover, the results of assimilative capacity per cultivated rice plant were also consistent with the above hypothesis (Fig. 2). Thus, these changes may represent some of the major underlying causes of the significant decline observed in cultivated rice yield. 
Conclusion: Our present study might conclude that photosynthetic and yield traits of cultivated rice could be severely affected by high density of weedy rice, including a reduction in $P_{\mathrm{N}}$, number of tillers, ratio of source to sink in increment, panicle increment rate, and mass of per 1000 seeds. Based on the comparison of photosynthesis and yield traits, our results indicated that weedy rice affected not only the photosynthetic characteristics of cultivated rice but also the grain-filling process through competition

\section{References}

Bilger W, Björkman O.: Role of the xanthophyll cycle in photoprotection elucidated by measurements of light-induced absorbance changes, fluorescence and photosynthesis in Hedera canariensis. - Photosynth. Res. 25: 173-185, 1990.

Burgos N.R., Norman R.J., Gealy D.R., Black H.: Competitive N uptake between rice and weedy rice. - Field Crop. Res. 99: 96105,2006

Cao S.Q., Zhang R.X, Tang Y.L. et al.: [A new index for identifying the relationship between leaf photosynthesis and grain filling at grain filling stage of rice.] - Acta Agron. Sin. 28: 516-520, 2002. [In Chinese]

Chauhan B.S., Johnson D.E.: Competitive interactions between weedy rice and cultivated rice as a function of added nitrogen and the level of competition. - Weed Biol. Manag. 11: 202209, 2011.

Dai X.B., Xu X.M., Lu W. et al.: Photoinhibition characteristics of a low chlorophyll $b$ mutant of high yield rice. Photosynthetica 41: 57-60, 2003.

Diarra A., Smith R.J., Talbert R.E. et al.: Interference of red rice (Oryza sativa) with rice (O. sativa). - Weed Sci. 33: 644-649, 1985.

Estorninos Jr. L.E., Gealy D.R., Talbert R.E.: Growth response of rice (Oryza sativa) and red rice (O Sativa) in a replacement series study. - Weed Technol. 16: 401- 406, 2002.

Ferrero A., Vidotto F., Balsari P. et al.: Mechanical and chemical control of red rice (Oryza sativa L. var. sylvatica) in rice (Oryza sativa L.) per-planting. - Crop Prot. 18: 245-251, 1999.

Genty B, Briantais J.M, Baker N.R.: The relationship between the quenching of photosynthetic electron transport and quenching of chlorophyll fluorescence. - Biochim. Biophys. Acta 990: 87-92, 1989.

Huang Y.M., Chen Q.F., Li Y.Z.: [Changes of sink-source characteristics during the cultivar improvement in rice in China.] - J. Fujian Agric. Univ. 27: 271-278, 1998. [In Chinese]

Jennings P.R., de Jesus J.: Studies on competition in rice. I. Competition in mixtures of varieties. - Evolution 22: 119-124, 1968.

Kwon S.L., Smith R.J., Talbert R.E.: Interference of red rice (Oryza sativa) densities in rice (O. sativa). - Weed Sci. 39: 169-174, 1991.

Li B.: Plant competition - In: Li B.(ed.): Experimental Study on Interaction of Crops and Weeds. Pp. 224-226. China Higher Educ. Press, Beijing 2001. [In Chinese]

Mortimer M., Pandey S., Piggin C.: Weedy rice: approaches to ecological appraisal and implications for research priorities. In: Baki B.B., Chin D.V., Mortimer M. (ed.): Wild and Weedy for light, space, nutrients, and other natural resources. The regression analysis suggested that the grain yield in cultivated rice was significantly correlated with accumulation of photosynthetic products as well as rates of grain filling and seed setting. Our results further indicated that the serious yield losses of cultivated rice might contribute to its reduced photosynthetic performance and accumulation of photosynthetic products under conditions of high density of weedy rice.

Rice in Rice Ecosystems in Asia - a Review. Pp. 97-105. Int. Rice Res. Inst., Los Baños 2000.

Noldin J.A.: Red rice status and management in the Americas. In: Baki B.B., Chin D.V., Mortimer M. (ed.): Wild and Weedy Rice in Rice Ecosystems in Asia - a Review. Pp. 21-24. Int. Rice Res. Inst., Los Baños 2000.

Pantone D.J., Baker J.B.: Reciprocal yield analysis of red rice (Oryza sativa) competition in cultivated rice. - Weed Sci. 39 42-47, 1991.

Schreiber U., Bilger W., Neubauer C.: Chlorophyll fluorescence as a nonintrusive indicator for rapid assessment of in vivo photosynthesis. - In: Schulze E.D, Caldwell M.M (ed.): Ecophysiology of Photosynthesis. Pp. 49-70. Springer, Berlin 1994.

Smith R.J.: Weed thresholds in southern U.S. rice (Oryza sativa). - Weed Technol. 2: 232-241, 1988.

Sun J.D., Xiao Y.C., Huang X.F. et al.: [Primary study on occurrence and control of weedy rice in japonica rice fields.] Weed Sci. 2: 21-23, 2005. [In Chinese]

Wang X.Y., Xu X.M., Cui J.: The importance of blue light for leaf area expansion, development of photosynthetic apparatus, and chloroplast ultrastructure of Cucumis sativus grown under weak light. - Photosynthetica 53: 213-222. 2015.

Wang W.X., Zhu T.H., Shao G.S. et al.: [Advance in study on taxonomy, origin, and utilization of weedy rice.] - Weed Sci. 2: 1-5, 2005. [In Chinese]

Yu G.Q., Bao Y, Shi C.H. et al.: Genetic diversity and population differentiation of Liaoning weedy rice detected by RAPD and SSR markers. - Biochem. Genet. 43: 261-270, 2005.

Zhai H.Q., Cao S.Q., Wan J.M.: Relationship between leaf photosynthetic function at grain filling stage and yield in super high-yielding hybrid rice (Oryza sativa. L). - Sci. China Life Sci. 45: 637-646, 2002.

Zhang C.X.: Wild and weedy rice in China. - In: Baki B.B., Chin D.V., Mortimer M. (ed.): Wild and Weedy Rice in Rice Ecosystems in Asia. Pp. 35-40. Int. Rice Res. Inst., Los Baños 2000.

Zhang R.X., Dai X.B., Xu X.M.: [Photosynthetic function of leaf and the potential photosynthetic productivity of crops.] - In: Lou C.H., Wang X.C. (ed.): [The Physiological Basis of Crop Yielding.] Pp. 52-63. China Agri. Press, Beijing 2001. [In Chinese]

Zhang W.Q., Linscombe S.D., Webster E. et al.: Risk assessment of the transfer of imazethapyr herbicide tolerance from Clearfield rice to red rice (Oryza sativa). - Euphytica 152: 75$86,2006$. 